UDC 343.1:342.84

LBC 67.410.2

\title{
CRIMINAL POLICY IN THE SPHERE OF SAFETY DURING PREPARATION AND CONDUCT OF ELECTIONS TO THE BODIES OF STATE POWER
}

\author{
Petr P. Muraev \\ FED Legal Company, Volgograd, Russian Federation \\ Natalya A. Solovyeva \\ Volgograd State University, Volgograd, Russian Federation
}

\begin{abstract}
Introduction: the criminal law policy is of great importance in law enforcement and represents the work of the state "mechanism" for planning activities of state scale and implementing the planned activities aimed at prevention and disclosure of crimes by improving the criminal law legislation and its application in practice.

The policy of combating administrative offenses and crimes shall be based on recognizingthe primacy of crime prevention overthe "punitive"policy, i.e. the reaction to already committed crimes.

In this regard, the authors of the article set a goal to determine the current state of the criminal law foundations of the activities of the internal affairs bodies of the Russian Federation and the Federal National Guard Troops Service to ensure the electoral rights of citizens and to assist electoral authorities in the conduct of elections. Results: the result of the work has been the author's standpointon the issue under study, based on the data of the sociological survey, the opinion of the academic community, based on the practical experience. Conclusions: the current state of the administrative and criminal law bases of activity of the considered structures allows carrying out safe and objective elections to the public authorities. However, increasing the efficiency of its use in certain areas requires further development in organizational and tactical, logistical, managerial and other areas.
\end{abstract}

Key words: security of the constitutional system, mechanism of the criminal law regulation, liberal democratic foundations, directions of implementing the legal framework in preparation and conduct of elections.

УДК $343.1: 342.84$

ББК 67.410 .2

\section{УГОЛОВНО-ПРАВОВАЯ ПОЛИТИКА В СФЕРЕ БЕЗОПАСНОСТИ ПРИ ПОДГОТОВКЕ И ПРОВЕДЕНИИ ВЫБОРОВ В ОРГАНЫ ГОСУДАРСТВЕННОЙ ВЛАСТИ}

\author{
Петр Петрович Мураев \\ Юридическая компания «ФЭД», г. Волгоград, Российская Федерация
}

Наталья Алексеевна Соловьева

Волгоградский государственный университет, г. Волгоград, Российская Федерация

\footnotetext{
Введение: уголовно-правовая политика имеет большое значение в правоохранительной деятельности и представляет собой работу государственного «механизма» по планированию мероприятий государственного масштаба и осуществлению намеченных мероприятий, направленных на профилактику совершения и раскрытие преступлений путем совершенствования уголовно-правового законодательства и применения его на практике.
} 
Политика противодействия административным правонарушениям, совершению преступлений должна строиться на признании приоритета предупреждения преступлений перед политикой «карательной», то есть реагированием на уже совершенные преступления.

В связи с этим авторы статьи поставили цель определить современное состояние уголовно-правовых основ деятельности органов внутренних дел Российской Федерации и военнослужащих Федеральной службы войск национальной гвардии по обеспечению избирательных прав граждан и содействию избирательным органам в проведении выборов. Результатом работы стала авторская позиция по изучаемому вопросу, основанная на данных социологического опроса, мнении научной среды, и сформулированная с опорой на практический опыт. Выводы: современное состояние административных и уголовно-правовых основ деятельности рассматриваемых структур позволяет осуществить проведение безопасных и объективных выборов в органы государственной власти. Однако повышение эффективности ее использования в отдельных направлениях требует дальнейшего развития в организационно-тактическом, материально-техническом, управленческом и других направлениях.

Ключевые слова: безопасность конституционного строя, механизм уголовно-правового регулирования, либерально-демократические основы, направления реализации правовых основ в подготовке и проведении выборов.

\section{Введение}

Правовая безопасность представляет собой социально-политическую структуру, которая функционирует в рамках правовой системы и с помощью права и законодательства о видах безопасности. Она несет в себе охрану, защиту права (обеспечение) и обеспеченность правового положения (правоотношений, состояний, статусов, правопорядка, условий, режимов и т. п.) субъектов (государства, общества, личности). В ее задачи входят предупреждение, нейтрализация, устранение опасностей, прежде всего социально-правовых (правонарушений), обеспечение законных прав, свобод и интересов личности, общества, государства или видов национальной безопасности [2; 4].

\section{Определение потенциальных угроз безопасности конституционного строя Российской Федерации}

В настоящее время существует проблема потенциальных угроз безопасности конституционного строя Российской Федерации. Их нельзя устранить с помощью механизмов уголовно-правового регулирования отношений в общественной жизни, в сфере охраны основ государственности. Как показывает практика, наука уголовного права в период после принятия нового уголовного закона так и не получила конструктивных предложений в деле обеспечения гарантий незыблемости имеющихся принципов, которые закреплены в ч. 1 ст. 1, ст. 2 и 3 Конституции РФ, то есть либерально-демократических основ.

Ст. 2 Конституции РФ гласит: «Человек, его права и свободы являются высшей ценностью. Признание, соблюдение и защита прав и свобод человека и гражданина - обязанность государства». Так, 18 марта 2018 г. большая часть общественности нашей страны избрала Президента Российской Федерации, то есть реализовала основополагающий конституционный принцип, который выступает одновременно основой уголовно-правовой политики и базовым, неопровержимым критерием. Данный принцип имеет в Российской Федерации значительное количество непримиримых политических противников, преследующих цель «исторического возврата» России в диктаторское прошлое либо установление не пережитой народом, взятой извне антидемократической системы прав и свобод граждан [5, с. 4].

\section{Значение пропаганды в обеспечении национальной безопасности}

Поскольку одним из мощных орудий указанных субъектов политической деятельности выступает пропаганда, действующий уголовно-правовой закон имеет определенный правовой барьер перед умышленным внедрением в общественное сознание (прежде всего - в умы молодежи) антилиберальных установок (взглядов, нивелирующих ценность ст. 2 Конституции РФ). В связи с этим в теории уголовно-правовой политики необходимо 
конкретизировать положение о том, что Конституция РФ провозглашает либеральную демократию, а также разработать определенный комплекс мер по обеспечению безопасности идеолого-политического фундамента основного закона от антиконституционных, в первую очередь антидемократических, угроз. Если не исключить такую вероятность уголовно-правовой политики, в конечном итоге это приведет к падению конституционного строя России и установлению антидемократического режима в стране.

Председатель Конституционного суда РФ В.Д. Зорькин отмечает, что «мы строим либеральное, открытое демократическое общество и рыночную экономику» [3], ведь и в содержании уголовного закона нет такой формулировки, что именно либерально-демократические принципы выступают в качестве объекта уголовно-правовой защиты, а ни в коем случае не интересы противоборствующих политических сил (в том числе религиозно-политические).

\section{Взаимодействие органов \\ внутренних дел с органами власти по обеспечению национальной безопасности}

В период подготовки и проведения выборов, как правило, проводятся общественнополитические и спортивно-развлекательные мероприятия с участием множества жителей городов, селений, а также гостей, прибывающих на эти мероприятия. Данные мероприятия часто проводятся в местах большого скопления людей. Как правило, органами внутренних дел и органами государственной безопасности во взаимодействии с сотрудниками избирательных комиссий принимаются необходимые меры правопорядка общественной безопасности, своевременного реагирования на складывающуюся обстановку, меры по предотвращению противоправных действий со стороны граждан, преступных намерений, недопущение подготовки и совершения террористических актов.

Для обеспечения правопорядка в местах избирательных участков задействуется большое количество сотрудников полиции, военнослужащих Федеральной службы войск нацио- нальной гвардии (Росгвардии). Координация управления приданными силами по охране общественного порядка осуществляется Центрами управления силами (ЦУС), расположенными в зданиях МВД Республик, ГУ МВД по областям, краям, УМВД городов, ОВД, имеющими в наличии необходимое оборудование и соответствующую технику. Сотрудниками ЦУС ведется постоянное наблюдения за событиями на избирательных участках в режиме реального времени, что дает возможность быстро принимать определенные решения и действовать по обстановке.

В рамках правовых основ деятельности правоохранительных органов и военнослужащих Федеральной службы войск национальной гвардии по обеспечению избирательных прав граждан и содействию избирательным органам в проведении выборов в сфере безопасности в соответствии с Конституцией РФ многонациональный народ является носителем суверенитета и единственным источником власти в государстве, а свобода выбора выступает высшим непосредственным выражением власти народа.

Согласно Федеральному закону от 12 июня 2002 г. № 67 «Об основных гарантиях избирательных прав и права на участие в референдуме граждан Российской Федерации» (с изм. от 5 декабря 2018 г., далее - Закон № 67) свободные демократические и периодические выборы в органы государственной власти, органы местного самоуправления являют собой высшее непосредственное выражение власти, которая принадлежит народу. Государство гарантирует свободное волеизъявление граждан Российской Федерации на выборах, защиту демократических принципов и норм избирательного права и права на участие в выборах.

\section{Правовые основы деятельности органов внутренних дел по обеспечению национальной безопасности}

Правовые основы деятельности органов внутренних дел по содействию избирательным органам в проведении выборов и обеспечении избирательных прав граждан закреплены в соответствующих нормативных правовых 
актах. Так, п. 5 ст. 20 Закона № 67 закрепляет, что избирательные комиссии имеют право обращаться в органы исполнительной власти, правоохранительные органы с требованием о проведении соответствующих проверок и о пресечении нарушений закона, а данные органы обязаны в течение пяти дней (перед днем голосования - если представление получено за пять и менее дней до дня голосования, а в день голосования или после него - немедленно) принять исчерпывающие меры по пресечению этих нарушений, а также в кратчайшие сроки проинформировать обратившуюся комиссию о полученных результатах. В случае, когда имеющиеся в представлении факты требуют дополнительной проверки, такие меры принимаются не позднее, чем в десятидневный срок.

В анализируемой ст. 20 Закона № 67 установлена также обязанность любой комиссии рассматривать в пределах своей компетенции обращения о нарушении законодательства о выборах, поступившие к ней в ходе подготовки и проведения выборов. При рассмотрении этих обращений избирательные комиссии должны проводить проверки по соблюдению законодательства о выборах, выявлять нарушителей законодательства. По результатам проверки избирательная комиссия, в которую поступило обращение, может передавать вопросы на повторное рассмотрение нижестоящим комиссиям, отменять их решения, принятые с нарушением законодательства, принимать собственное решение по существу обращения, применять установленные законом меры воздействия к лицам, допустившим нарушение законодательства о выборах, в том числе направлять материалы проверки в органы местного самоуправления, иные органы и обращаться в суд. Обязанность правоохранительных органов - незамедлительно принимать меры по пресечению нарушений законодательства о выборах. При обращении соответствующих комиссий они призваны обеспечить активную и целенаправленную защиту прав граждан Российской Федерации, нарушенных в ходе выборов.

Помимо сказанного, правоохранительные органы должны принимать меры к пресечению незаконной агитационной деятельности, предотвращать тиражирование либо осуществлять изъятие подложных печатных, аудио- визуальных и иных пропагандистских материалов, устанавливать их изготовителей и тех, кто оплатил услуги, а также незамедлительно информировать о выявленных фактах и принятых мерах соответствующую избирательную комиссию.

Пункты 8 и 9 ст. 56 Закона № 67 устанавливают обязанность органов исполнительной власти и суда, правоохранительных органов, которые контролируют сферу массовых коммуникаций, принимать от избирательной комиссии заявления о пресечении противоправной пропагандистской деятельности и привлечении редакции периодического печатного издания, организации телерадиовещания, их должностных лиц к ответственности, установленной законодательством Российской Федерации, если они нарушили установленный порядок проведения агитации [1].

Задачи органов внутренних дел по обеспечению порядка на выборах и референдумах закреплены в Федеральном законе от 7 февраля 2011 г. № 3-Ф3 «О полиции» и вытекают из общих обязанностей, возложенных на полицию. Согласно ст. 12 указанного закона, полиция обязана: содействовать кандидатам, зарегистрированным кандидатам в депутаты или на выборные должности в органах государственной власти, органах местного самоуправления, депутатам представительных органов государственной власти, органов местного самоуправления, должностным лицам органов государственной власти и органов местного самоуправления, членам избирательной комиссии, представителям общественных объединений в осуществлении их законной деятельности, если им оказывается противодействие или угрожает опасность.

Противодействие являет собой действие или бездействие, которое создает препятствие законной деятельности перечисленных лиц, квалифицируемое преступлением или административным правонарушением, либо не содержит в себе состава правонарушения (например, при невменяемости субъекта).

«Угроза опасности», в свою очередь, взаимосвязана с исполнением указанными лицами своего специального статуса. Она может выражаться в угрозе их собственной жизни и здоровью, здоровью и жизни их близких, имуществу и т. д. 
В понятие «содействие» включаются действия различного характера - и предоставление необходимой информации в соответствии с законом, и силовое (разумеется, в рамках закона) вмешательство. При этом полицию нельзя привлекать к политической агитации и иным формам политической активности, так как эти действия противоречат принципам политического нейтралитета государственной службы.

Также в ст. 12 Федерального закона от 7 февраля 2011 г. № 3-Ф3 «О полиции» указано, что в обязанности полиции входит содействие избирательным комиссиям в реализации их полномочий, включая предоставление им сведений о наличии неснятой или непогашенной судимости у кандидатов, зарегистрированных кандидатов в депутаты или на выборные должности в органах государственной власти, органах местного самоуправления. Возложение на полицию названной обязанности целесообразно считать одним из средств правового обеспечения эффективной и целенаправленной деятельности избирательных комиссий. Содержание содействия полиции избирательным комиссиям в полной мере в законодательстве не раскрывается.

Ст. 2 Закона РФ от 28 декабря 2010 г. № 390-Ф3 «О безопасности» гласит, что основой деятельности системы обеспечения общественной безопасности, в которую входят органы и подразделения МВД России, являются следующие принципы: соблюдения и защиты прав и свобод человека и гражданина; комплексности и системности применения федеральными органами государственной власти, органами государственной власти субъектов РФ, другими государственными органами правовых и иных мер обеспечения безопасности; приоритета предупредительных мер для обеспечения безопасности; законности; взаимодействия федеральных органов государственной власти, органов государственной власти субъектов РФ, других государственных органов с общественными объединениями, международными организациями и гражданами в целях обеспечения безопасности.

Федеральным законом от 6 марта 2006 г. № 35-Ф3 «О противодействии терроризму» (с изм. от 6 июля 2016 г.) установлены организационные и правовые основы деятельнос- ти, направленной на борьбу с терроризмом в нашей стране, разъяснен порядок координации функционирования федеральных органов исполнительной власти, ведущих борьбу с терроризмом, органов исполнительной власти субъектов РФ, общественных организаций и объединений, должностных лиц, отдельных граждан, а также права, обязанности и гарантии граждан в связи с организацией и проведением борьбы с терроризмом.

К числу общих задач, определенных нормативными правовыми актами, относятся:

- обеспечение государственной, общественной и личной безопасности и охрана общественного порядка;

- предупреждение и пресечение попыток совершить террористические акты и иные преступления и административные правонарушения возле мест и в помещениях для голосования, в местах массового скопления граждан, на объектах промышленности и жизнеобеспечения;

- активизация работы оперативных подразделений по выявлению лиц, подготавливающих противоправные действия, цель которых - срыв выборов.

При закрытии избирательных участков после голосования, если имелись какие либо нарушения при проведении выборов, сотрудники прокуратуры, органов полиции совместно с членами органов власти составляют общий протокол (меморандум) по проведению выборов, где описывают общее проведение выборов и указывают недостатки, если они имеются. После чего с сотрудниками управления юстиции выносятся выводы, дается оценка правильности проведения и работы организаторов выборов в соответствии с Федеральным законом.

Представители органов власти, которые наделены полномочиями, если имеются для этого основания, обращаются в суд с исковыми заявлениями об ущербе, нанесенном противоправными действиями со стороны граждан.

\section{Выводы}

Таким образом, нами были рассмотрены основные задачи по обеспечению посредством уголовно-правовых норм правопорядка и безопасности, недопущения террористи- 
ческих актов при подготовке и проведении выборов в органы государственной власти, особенности организации деятельности органов внутренних дел по обеспечению общественного порядка, безопасности и недопущению террористических актов в этот период, а также алгоритм действий сотрудников органов внутренних дел в различных ситуациях. На основе исследования специальной литературы и применения опыта практической деятельности органов внутренних дел авторами выработана система действий и мероприятий, необходимая для практической организации несения службы в период подготовки и проведения выборов в органы государственной власти. Анализ деятельности органов внутренних дел показал, что успех охраны общественного порядка и общественной безопасности при подготовке и проведении рассматриваемых мероприятий во многом зависит от четкой, последовательной и целенаправленной деятельности оперативного штаба, знаний, умений и квалификации сотрудников.

\section{СПИСОК ЛИТЕРАТУРЫ}

1. Васильева, В. И. Комментарий к Федеральному закону «Об основных гарантиях избирательных прав и права на участие в референдуме граждан Российской Федерации» / В. И. Васильева, А. А. Вешнякова, В. И. Лысенко. - М. : НОРМА, 1999. - 760 с. - Доступ из справ.-правовой системы «КонсультантПлюс».

2. Кольжанов, И. В. Конституционно-правовые основы реализации гражданами Российской Федерации избирательных прав: вопросы теории и практики : дис. ... канд. юрид. наук / Кольжанов Игорь Валерьевич. - М., 2004. - 153 с.

3. Комментарий к Конституции Российской Федерации / под ред. В. Д. Зорькина. - 3-е изд., пересмотр. - М. : НОРМА : ИНФРА-М, 2013.- 1040 с.

4. Мураев, П. П. Особенности обеспечения общественного порядка при подготовке и проведении выборов в органы государственной власти : учеб. пособие / П. П. Мураев, В. И. Косяченко. - 2-е изд. Волгоград : ВА МВД России, 2013. - 130 с.

5. Сергун, Е. П. Уголовно-правовая политика в сфере обеспечения безопасности конституционного строя Российской Федерации : автореф. дис. ... канд. юрид. наук / Сергун Евгений Петрович. - М., 2014. -40 c.

\section{REFERENCES}

1. Vasilyeva V.I., Veshnyakova A.A., Lysenko V.I. Kommentariy k Federalnomu zakonu «Ob osnovnyh garantiyah izbiratelnyh prav i prava na uchastie $v$ referendume grazhdan Rossiyskoy Federatsii» [Commentary on the Federal Law 'On Basic Guarantees of Electoral Rights and the Right to Participate in the Referendum of Citizens of the Russian Federation']. Moscow, NORMA Publ., 1999. 760 p.

2. Kolzhanov I.V. Konstitutsionno-pravovye osnovy realizatsii grazhdanami Rossiyskoy Federatsii izbiratelnykh prav: voprosy teorii $i$ praktiki: dis. ... kand. yurid. nauk [Constitutional and Legal Bases for Implementation of Electoral Rights by Citizens of the Russian Federation: Issues of Theory and Practice. Cand. jurid. sci. diss.]. Moscow, 2004. 153 p.

3. Zorkin V.D., ed. Kommentariy k Konstitutsii Rossiyskoy Federatsii [Commentary on the Constitution of the Russian Federation]. Moscow, NORMA Publ.: INFRA-M Publ., 2013. 1040 p.

4. Muraev P.P., Kosyachenko V.I. Osobennosti obespecheniya obshchestvennogo poryadka pri podgotovke $i$ provedenii vyborov $v$ organy gosudarstvennoy vlasti: ucheb. posobie [Ensuring Public Order When Preparing and Holding Elections fto Public Authorities: Textbook]. Volgograd, VA MVD Rossii Publ., 2013. 130 p.

5. Sergun E.P. Ugolovno-pravovaya politika v sfere obespecheniya bezopasnosti konstitutsionnogo stroya Rossiyskoy Federatsii: avtoref. dis. ... kand. yurid. nauk [Criminal and Legal Policy in the Sphere of Ensuring the Security of the Constitutional System of the Russian Federation. Cand. jurid. sci. abs. diss.]. Moscow, 2014. 40 p. 
П.П. Мураев, Н.А. Соловьева. Уголовно-правовая политика в сфере безопасности при проведении выборов

\section{Information about the Authors}

Petr P. Muraev, Candidate of Sciences (Jurisprudence), Associate Professor, Consultant of FED Legal Company, Adzharskaya St., 16/1, 400116 Volgograd, Russian Federation, petr.muraev@mail.ru.

Natalya A. Solovyeva, Candidate of Sciences (Jurisprudence), Associate Professor, Head of Department of Criminal Procedure and Criminalistics, Institute of Law, Volgograd State University, Prosp. Universitetsky, 100, 400062 Volgograd, Russian Federation, natalisoul13@mail.ru.

\section{Информация об авторах}

Петр Петрович Мураев, кандидат юридических наук, доцент, консультант юридической компании «ФЭД», ул. Аджарская, 16/1, 400116 г. Волгоград, Российская Федерация, petr.muraev@mail.ru.

Наталья Алексеевна Соловьева, кандидат юридических наук, доцент, заведующая кафедрой уголовного процесса и криминалистики института права, Волгоградский государственный университет, просп. Университетский, 100, 400062 г. Волгоград, Российская Федерация, natalisou113@mail.ru. 